\title{
An investigation of latitudinal transitions in the SuperDARN Doppler spectral width parameter at different magnetic local times
}

\author{
G. Chisham and M. P. Freeman \\ British Antarctic Survey, Natural Environment Research Council, High Cross, Madingley Road, Cambridge, CB3 0ET, UK
}

Received: 12 June 2003 - Revised: 28 August 2003 - Accepted: 4 September 2003 - Published: 2 April 2004

\begin{abstract}
Latitudinal transitions from low to high Doppler spectral width in backscatter measured by the Super Dual Auroral Radar Network (SuperDARN) are now routinely used as proxies for the polar cap boundary (PCB) in the cusp-region ionosphere. In this paper we perform a statistical study of the nature of similar spectral width transitions at other magnetic local times (MLTs). This analysis illustrates that these latitudinal spectral width transitions exist at all magnetic local times, and that the latitude, gradient, and amplitude of the transitions vary systematically with MLT. In particular, the probability of a transition occurring at any latitude, identified independently in each MLT sector, is continuous with MLT from the cusp, through the morning sector, to the nightside. This suggests that the transition represents the PCB, as this is known to be what it represents in the cusp region. However, the picture in the afternoon sector (12:0018:00 MLT) is more complex with no clearly preferred transition latitudes.
\end{abstract}

Key words. Ionosphere (ionosphere-magnetosphere interactions; instruments and techniques). Magnetospheric physics (magnetopause, cusp, and boundary layers.)

\section{Introduction}

The polar cap boundary (PCB) in the ionosphere is the separatrix between the footprints of closed geomagnetic flux and open magnetic flux interconnected with the interplanetary magnetic field (IMF). By identifying and tracking the location of this boundary, the electrodynamics of the magnetospheric system can be investigated, specifically, the magnetic reconnection rate (Pinnock et al., 2003) and the associated addition and removal of open magnetic flux from the polar cap during the substorm cycle (Milan et al., 2003). A wide range of signatures of the PCB have been identified, including particle precipitation signatures measured by low-altitude spacecraft (Evans and Stone, 1972; Newell and Meng, 1992, 1994), optical signatures of precipitation from

Correspondence to: G. Chisham

(g.chisham@bas.ac.uk) all-sky cameras, spacecraft imagers, and meridian-scanning photometers (Lockwood et al., 1993; Blanchard et al., 1995, 1997; Sandholt et al., 1998; Moen et al., 2001; Khan et al., 2003), E-region electron density signatures from incoherent scatter radar (de la Beaujardière et al., 1994; Blanchard et al., 1996, 2001), the equatorward edge of HF radar backscatter (Milan et al., 1999; Milan and Lester, 2001), and the Doppler spectral width boundary (SWB) from the Super Dual Auroral Radar Network (SuperDARN) (Baker et al., 1995, 1997; Pinnock and Rodger, 2001; Chisham et al., 2001, 2002). Each of the different instrumental techniques has its strengths and weaknesses (for a detailed discussion, see Chisham and Freeman, 2003), but they compare well in the ionospheric cusp, under IMF $B_{z}<0$ conditions (Rodger et al., 1995; Yeoman et al., 1997; Milan et al., 1999).

The Doppler spectral width of backscatter measured by the SuperDARN radars (Greenwald et al., 1995) is a measure of the spatial and temporal structure in the ionospheric electric field on scales comparable to, or less than, the radar integration period $(\sim 10 \mathrm{~s})$, and the spatial area of the radar observation cell $(\sim 100 \mathrm{~km}$ square $)$. This structure is a complex convolution of a number of factors (André et al., 2000b):

1. The effect of temporally varying electric fields in the ionosphere (André et al., 1999, 2000a, 2002; Villain et al., 2002); Pc1/2 wave activity is often observed in the cusp by low-altitude satellites (Maynard et al., 1991; Matsuoka et al., 1993) and throughout the auroral oval (Gurnett, 1991). However, an error in the simulations of André et al. $(1999,2000 \mathrm{a})$ has recently been highlighted (Ponomarenko and Waters, 2003), and the importance of Pc1/2 wave activity is still unclear.

2. The geometry of the radar with respect to the large-scale convection pattern (Villain et al., 2002). Some observation orientations are more sensitive to large-scale velocity shears in ionospheric convection.

3. The presence of meso-scale inhomogeneities of the scale size of a range/beam cell $(\sim 10-100 \mathrm{~km})$. Velocity shears and small-scale $(<\sim 26 \mathrm{~km})$, short-lived ( $<\sim 4 \mathrm{~s})$ vortices can result from the radial electric fields 
produced around filamentary electron precipitation (Huber and Sofko, 2000).

4. The effect of microscale turbulence $(\sim 10 \mathrm{~m})$ (André et al., 2000b).

The spatial variation in the Doppler spectral width measured by the SuperDARN radars is best understood in the cuspregion ionosphere (Baker et al., 1995; Hosokawa et al., 2002; Chisham and Freeman, 2003). Under conditions of IMF $B_{z}<0$, the character of the spectral width changes markedly at the equatorward edge of the cusp (as defined by Newell and Meng, 1992), from low spectral width values equatorward of the cusp, to large, variable spectral width values within the cusp itself. This transition typically occurs over less than a few degrees of latitude. The distributions of spectral width values have been described as being approximately Gaussian (with a median value in the range of $200-400 \mathrm{~m} / \mathrm{s}$ ) in the cusp, and exponential (with a median value in the range of $50-150 \mathrm{~m} / \mathrm{s}$ ) in the sub-cusp region (Baker et al., 1995).

Understanding of the variation in spectral width away from the cusp-region ionosphere is also increasing. Ionospheric maps of the average spectral width show moderately high average values in an oval region similar to the auroral oval (André et al., 2002; Villain et al., 2002). However, the peak average value in this oval varies with magnetic local time (MLT), maximising in the cusp region. In the nightside ionosphere, a sharp SWB, similar to the transition typically observed in the cusp region, has been observed (Woodfield et al., 2002a,b; Parkinson et al., 2002). However, it is unclear to what physical boundary this nightside SWB corresponds. It has been suggested that the nightside transition represents either the PCB (Lester et al., 2001; Parkinson et al., 2002), or the boundary between the central plasma sheet (CPS) and the plasma sheet boundary layer (PSBL) (Dudeney et al., 1998). Woodfield et al. (2002a) suggested that one possible mechanism for generating high spectral widths on the nightside is the presence of particle precipitation (as in the cusp region). Woodfield et al. (2002b,c) further concluded that the SWB on the nightside can be located on closed field lines and hence, does not always represent a good proxy for the PCB. These studies also suggested that the relationship between different nightside spectral width regions and the ionospheric footprints of magnetospheric regions may change during substorms and other dynamic magnetospheric events, and also with MLT.

Although there has been considerable progress understanding spectral width variations on the nightside, there has been little study of latitudinal variations in spectral width in the regions of the ionosphere which map to the flank region magnetosphere. Full statistical comparisons with other datasets are still needed to clarify what latitudinal spectral width transitions represent in all MLT sectors.

Identifying the SWB in the cusp region has sometimes been subjective (Milan et al., 1999), but more objective threshold techniques have also been used (Baker et al., 1997; Pinnock et al., 1999; Chisham et al., 2001). These techniques involve choosing a spectral width threshold above which the spectral width values are most likely to originate from the cusp spectral width distribution, and developing an algorithm which searches poleward along a radar beam until this threshold is exceeded. The technique is not very accurate in this basic form, as the probability distributions of the spectral width values above and below the SWB are typically broad and have considerable overlap. The inclusion of additional rules in the threshold algorithm increases the accuracy of the boundary determination considerably (Chisham and Freeman, 2003).

In this paper, we use the spectral width threshold algorithm defined by Chisham and Freeman (2003) - hereafter referred to as the "C-F threshold technique" - to investigate the latitude, gradient and amplitude of spectral width transitions at all MLTs, and the form of the spectral width distributions that exist on either side of the transition. We also determine the probability of a transition occurring at any latitude and MLT. Understanding the nature of the transitions and their occurrence distributions at all MLTs will allow for more accurate identification of geophysical boundaries away from the cusp region.

\section{The C-F threshold technique}

In this section we outline details of the C-F threshold technique for identifying latitudinal transitions in SuperDARN spectral width data sets. Chisham and Freeman (2003) showed that spatially and temporally median filtering the spectral width data set improved the reliability of the estimation of the SWB location using a threshold criterion.

For much of the time the SuperDARN radars work in a common mode of operation during which each radar beam comprises $\sim 70$ range gates with a range separation of $45 \mathrm{~km}$, and for which the radar integration time is $\sim 7$ seconds. In this mode the radar takes 2 min to perform a complete scan of its field of view. The C-F threshold technique, when applied to this common mode data, is as follows:

1. Remove ground backscatter and backscatter with a power of less than $3 \mathrm{~dB}$ from the SuperDARN data set.

2. For each radar scan $n$, select the meridional beam $j$ (representing the beam most likely to show the clearest boundaries), and the beam on either side of it $(j \pm 1)$. For each range gate $i$, take the median of the spectral width values $w$ for these three beams to represent the spectral width at that range gate on the meridional beam $\left(\tilde{w}_{i, j}^{n}=\operatorname{Median}\left[w_{i, j-1}^{n}, w_{i, j}^{n}, w_{i, j+1}^{n}\right]\right)$. This represents the initial spatial filtering.

3. Take the median-filtered, meridional-beam, spectral width values $\tilde{w}_{i, j}^{n}$ from 5 consecutive scans $(n-2, n-1, n, n+1, n+2)$ and perform a similar process, taking the median values of these 5 scans $\left(\bar{w}_{i, j}^{n}=\operatorname{Median}\left[\tilde{w}_{i, j}^{n-2}, \tilde{w}_{i, j}^{n-1}, \tilde{w}_{i, j}^{n}, \tilde{w}_{i, j}^{n+1}, \tilde{w}_{i, j}^{n+2}\right]\right)$.

These spectral width values then represent the variation with range for the central of these 5 scans (this represents the temporal filtering). If temporal data gaps exist 
in the data set, then at least 3 out of 5 values must exist to provide a filtered spectral width value.

4. For each median-filtered beam, starting at the first spectral width value below the chosen spectral width threshold value $c$, search poleward up the meridional beam until a spectral width value that exceeds the chosen threshold value is reached, at range gate $i=k\left(\bar{w}_{k, j}^{n}>c\right)$.

5. Examine the three spectral width values poleward of the estimated boundary location. If the median of these 3 values is also greater than the chosen threshold value (Median $\left[\bar{w}_{k+1, j}^{n}, \bar{w}_{k+2, j}^{n}, \bar{w}_{k+3, j}^{n}\right]>c$ ) then a boundary has been identified. This process represents further spatial filtering. If this criterion is not satisfied then we continue searching along the beam, repeating steps (4) and (5) until a boundary is identified, or we reach the end of the data in the beam, in which case there is no boundary identification at this time. If a spatial data gap of more than 2 range gates is encountered during the search along a beam, then the search process restarts with step (4) at the next range gate containing good data.

When applying this technique to non-common mode data, the algorithm must be altered, depending on the mode of operation of the radar. For intervals of high-time resolution data on single beams, for example, the initial spatial filtering in step (2) can be removed, and the number of scans used for the temporal filtering in step (3) can be increased, to achieve the same level of accuracy. The choice of the optimum threshold value depends on the spectral width distributions that exist on either side of the latitudinal transition in spectral width that we wish to locate. It should be chosen so that it is midway between the medians of the above and below-boundary distributions. However, since these distributions are not known a priori, the technique should be tried with a number of threshold values. Repeating the technique with different spectral width threshold values allows an evaluation of the gradient and amplitude of a transition.

Figure 1 presents four hypothetical scenarios which display a spectral width transition from a low-latitude to a highlatitude spectral width distribution over a few degrees of geomagnetic latitude. In each scenario the blue line represents the variation of the median of the spectral width distribution with latitude and the grey area is the approximate half-width of the distribution. The four horizontal lines represent four different spectral width threshold values, $150 \mathrm{~m} / \mathrm{s}$ (black), $200 \mathrm{~m} / \mathrm{s}$ (green), $250 \mathrm{~m} / \mathrm{s}$ (yellow), and $300 \mathrm{~m} / \mathrm{s}$ (red). The four dashed vertical lines of the same colour represent the best estimates of where a boundary will be determined when applying the technique with these threshold values (typically when the threshold value equals the local median of the distribution). The four scenarios can be described in detail as follows: (a) This illustrates a transition with a sharp gradient (similar to that typically seen in the cusp region) occurring across a small latitudinal region $\left(\sim 1^{\circ}\right)$. There is a large amplitude change between the high and low-latitude spectral width distributions and the four spectral width thresh-

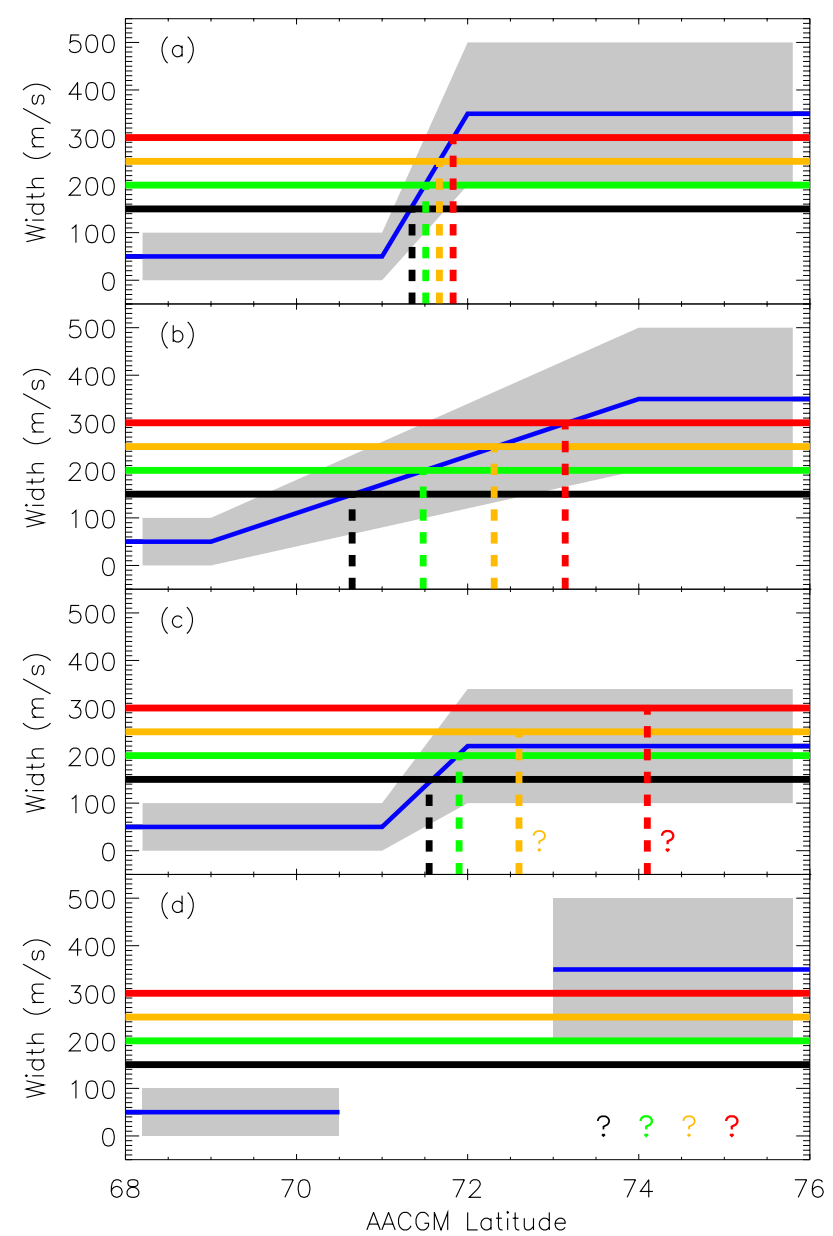

Fig. 1. Four possible spectral width transition scenarios (see text for full details). In each panel the blue line represents the variation of the median of the spectral width distribution with latitude and the grey area is the approximate half-width of the distribution. The four horizontal lines represent four different spectral width threshold values, $150 \mathrm{~m} / \mathrm{s}$ (black), $200 \mathrm{~m} / \mathrm{s}$ (green), $250 \mathrm{~m} / \mathrm{s}$ (yellow), and $300 \mathrm{~m} / \mathrm{s}$ (red). The four dashed vertical lines represent the best estimate of where a boundary will be determined. The question marks signify a questionable or non-existant boundary determination.

old values are all located between the median values of these two distributions, and are hence most likely to be triggered within the transition region (i.e. at the true boundary location). Hence these four thresholds will identify almost identical boundary locations.

(b) This illustrates a transition with a shallow gradient where no sharp boundary exists. Although there is still a large amplitude change between the two spectral width distributions, the four spectral width threshold values will trigger at different locations within the transition due to the lack of a sharp boundary.

(c) This illustrates a transition with a sharp gradient (similar to a). However, in this scenario the change between the high and low-latitude spectral width distributions is of a lower amplitude. Two of the chosen threshold values are 


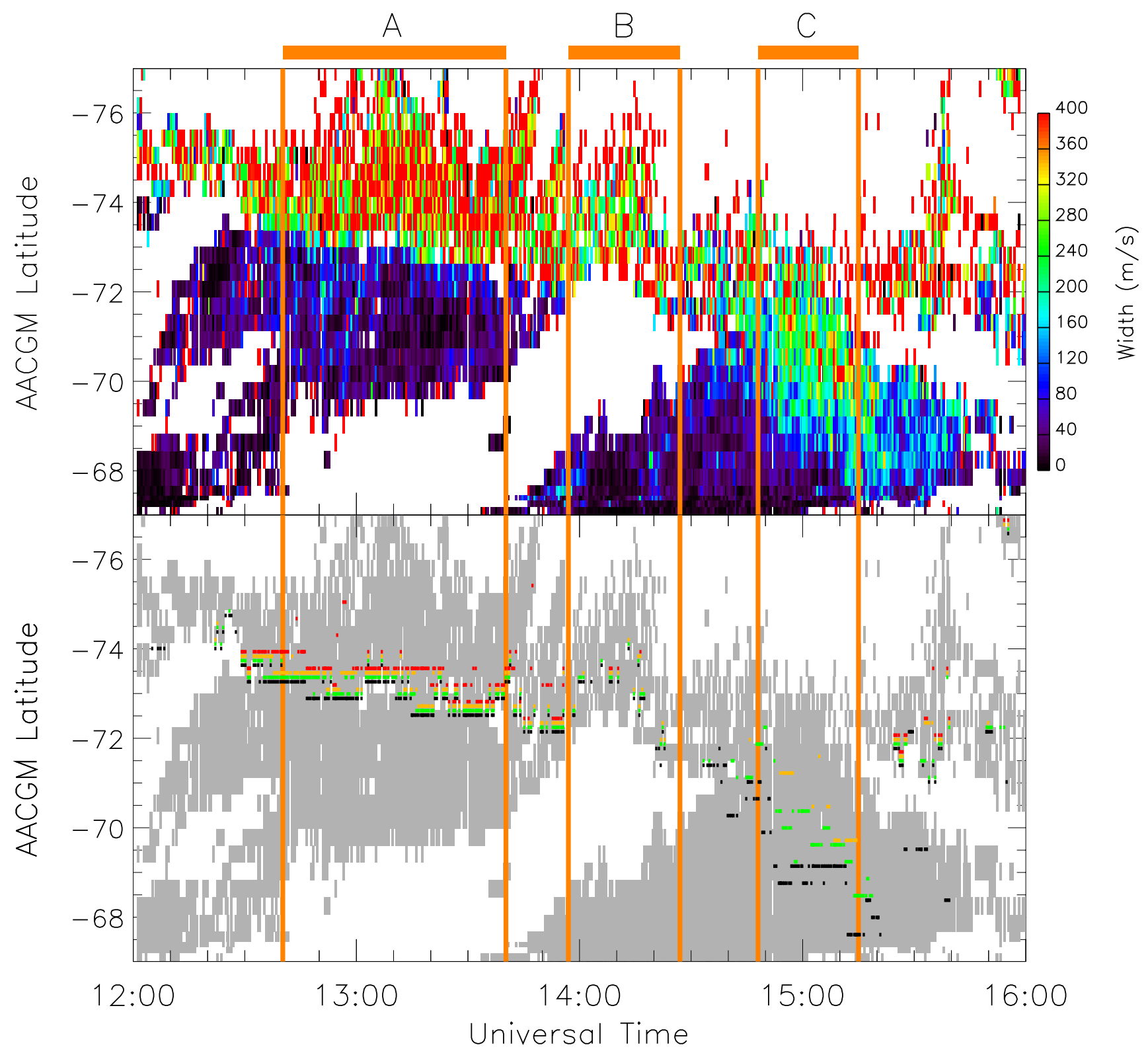

Fig. 2. The top panel presents the unfiltered spectral width variation observed by Halley beam 4 on August 14, 1998. The lower panel presents the results of boundary determinations when applying different spectral width threshold values, $150 \mathrm{~m} / \mathrm{s}$ (black), $200 \mathrm{~m} / \mathrm{s}$ (green), $250 \mathrm{~m} / \mathrm{s}$ (yellow), and $300 \mathrm{~m} / \mathrm{s}$ (red). The orange lines and orange bars highlight three time intervals that are studied in detail, interval A (12:40-13:40 UT), interval B (13:56-14:28 UT), and interval C (14:48-15:15 UT).

now larger than the high-latitude median spectral width. The two lower threshold values are most likely to trigger at the boundary location, but the two higher threshold values may not. They could trigger anywhere within the high-latitude spectral width region. There is also the chance that they will not trigger at all if the high-latitude spectral width region is limited in latitude. For this particular transition, a different choice of thresholds (say between 100 and $200 \mathrm{~m} / \mathrm{s}$ ) would provide a more accurate and better-resolved boundary estimate.

(d) In this scenario, a data gap exists between the high and low-latitude spectral width regions. The location and gradi- ent of the transition are indeterminate as the boundary could be located anywhere within the data gap. As the search algorithm includes the condition that the beam search is initiated only at a value below the spectral width threshold value, boundaries will rarely be identified in such a data set. When they are, they are likely to be unreliable.

\section{An Example Application of the Technique}

In this section we present an example of the application of the technique as described above. The focus in this example 
is understanding the nature of the transition between the different spectral width regions; how sharp is the gradient of the transition and what is the amplitude of the change between the two distributions above and below the boundary?

On 14 August 1998, the Halley SuperDARN radar observed a long interval of continuous backscatter from approximately 12:00 to 16:00 UT (magnetic local noon is approximately 15:00 UT for Halley beam 8). During this interval the radar was operating in a special mode with beams 2,3 , and 4 operating at a high temporal resolution ( $\sim 30$ s sampling) and all other beams operating at a lower temporal resolution. Figure 2 (top panel) presents the spectral width variation observed by Halley beam 4 (at high-time resolution) during this interval. Beam 4 is directed at $\sim 13^{\circ}$ anticlockwise from the geomagnetic meridional direction. Early in this interval the backscatter displays the latitudinal spectral width variation typically associated with the cusp - high, variable spectral width values poleward of a region of low spectral width values. The latter part of the interval (after 14:00 UT) presents a more complex picture, although there still exists a high, variable spectral width region at higher latitudes and a low spectral width region at low latitudes.

We have employed the C-F threshold technique to estimate the SWB location during this interval. We applied temporal median filtering only (increased to 9 scans) to the Halley beam 4 data (the initial spatial filtering is inappropriate for this special mode data set). The analysis was repeated using four spectral width threshold values $(150,200,250$, and $300 \mathrm{~m} / \mathrm{s}$ ). The results of the boundary determinations are presented in the bottom panel of Fig. 2. The grey shading represents the region of data coverage as shown in the top panel. The coloured horizontal line segments represent the boundary determinations for the different spectral width threshold values, $150 \mathrm{~m} / \mathrm{s}$ (black), $200 \mathrm{~m} / \mathrm{s}$ (green), $250 \mathrm{~m} / \mathrm{s}$ (yellow), and $300 \mathrm{~m} / \mathrm{s}$ (red). The boundaries determined for each threshold value have been shifted slightly in latitude so that they do not obscure the other results when the estimated boundary locations for different threshold values are identical.

In Fig. 2 we have highlighted three distinctly different intervals, A (12:40-13:40 UT), B (13:56-14:28 UT) and C (14:48-15:15 UT), within which boundary determinations have been made. These intervals are delineated by the vertical orange lines and the horizontal orange bars. During interval A, the boundary estimates for the different thresholds are almost always identical, similar to the schematic representation in Fig. 1a. This represents an excellent boundary determination; a sharp transition between two contrasting spectral width distributions. During interval B there exists a large data gap between the high, variable spectral width values at high latitudes, and the low spectral width values at low latitudes, similar to the schematic representation in Fig. 1d. During this interval, very few boundary identifications have been made, and those that have are unreliable. The scenario during interval C is not totally clear. Although the spectral width values increase statistically with latitude, it is not clear that there is a sharp transition between the low and high-latitude

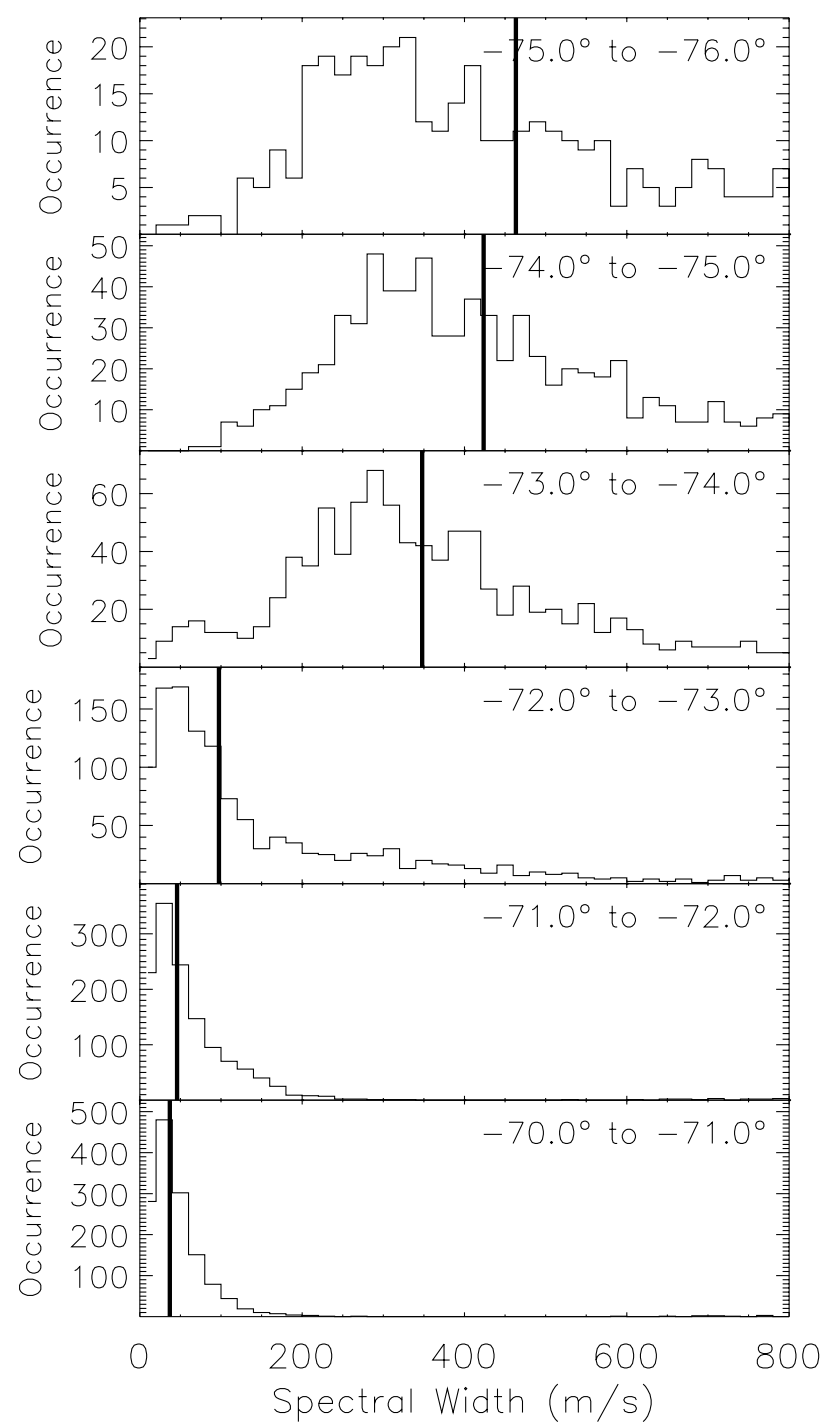

Fig. 3. The distributions of spectral width from all beams of the Halley radar measured during the interval 12:40-13:40 UT (interval A) on 14 August 1998. The distributions have been split into $1^{\circ}$ latitude bins from $-70^{\circ}$ to $-76^{\circ}$. The bold vertical lines represent the medians of each distribution.

spectral width distributions. During interval $\mathrm{C}$ it is only when using the lower threshold values that a boundary is consistently identified, and the boundary locations vary when employing different threshold values. It is possible that this is a result of a shallow transition (as in Fig. 1b), or of a low amplitude change between the distributions above and below the boundary (as in Fig. 1c). The latter seems the more likely scenario as there are very few boundaries observed when applying the higher threshold values.

In order to study these spectral width transitions in more detail we take a closer look at the latitudinal variations in the spectral width distributions for each of these intervals. We use data from all the Halley beams (0-15), which are all oriented within $\sim 30^{\circ}$ of the meridional direction. Figure 3 presents the distributions of the spectral width values 


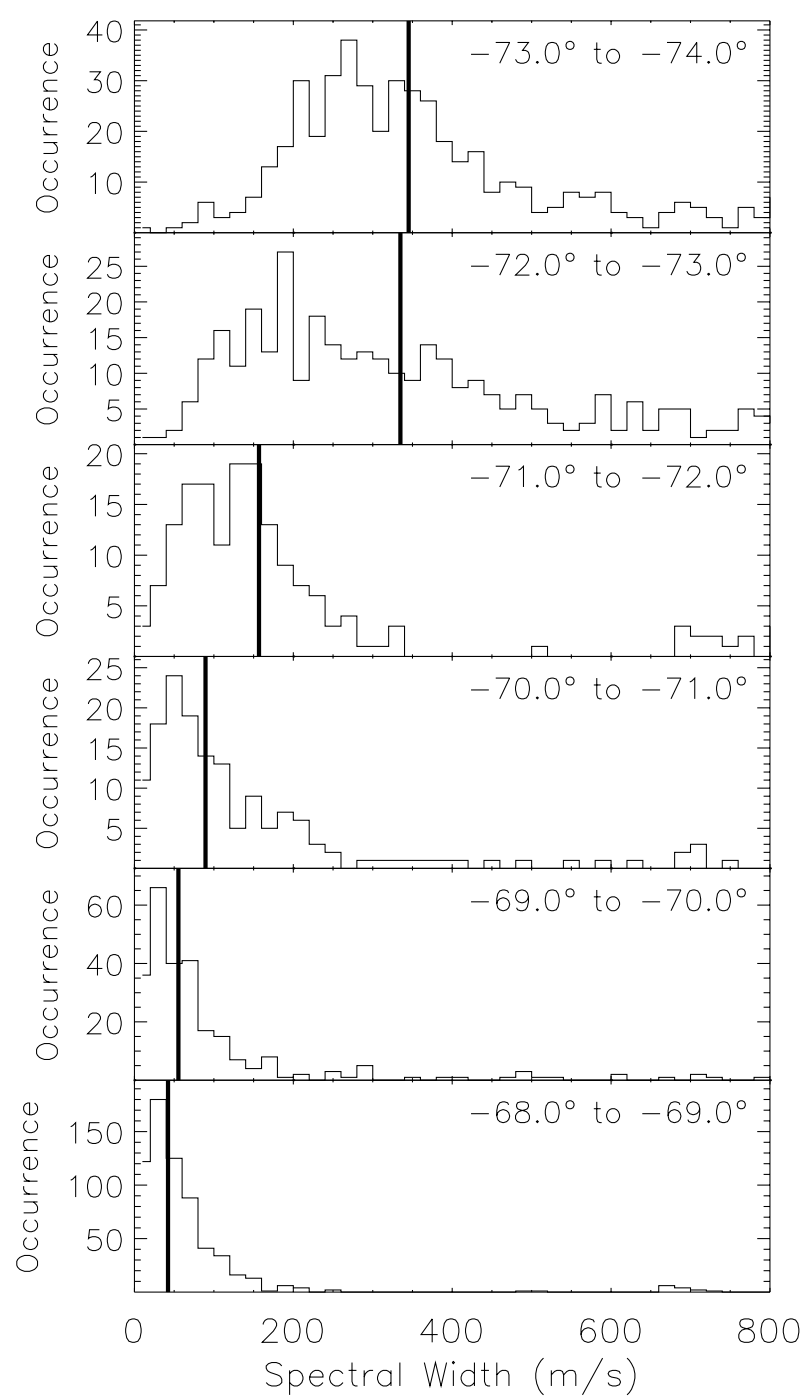

Fig. 4. The distributions of spectral width from all beams of the Halley radar measured during the interval 13:56-14:28 UT (interval B) on 14 August 1998. The distributions have been split into $1^{\circ}$ latitude bins from $-68^{\circ}$ to $-74^{\circ}$. The bold vertical lines represent the medians of each distribution.

for interval $\mathrm{A}$ for the geomagnetic latitude range $-70^{\circ}$ to $-76^{\circ}$, separated into $1^{\circ}$ latitude bins. The bold vertical line in each panel represents the median of the associated distribution. At low latitudes the distributions have median values below $100 \mathrm{~m} / \mathrm{s}$ and are similar to the below-boundary distributions presented by Chisham and Freeman (2003) and the LLBL distributions presented by Baker et al. (1995). At high latitudes the distributions have median values $\sim 350-450 \mathrm{~m} / \mathrm{s}$ and are similar to the above-boundary distributions presented by Chisham and Freeman (2003) and the cusp distributions presented by Baker et al. (1995). Baker et al. (1995) described the below-boundary distributions as exponential and the above-boundary distributions as Gaussian. We use these labels in this paper for convenience but the distributions are not actually Gaussian or exponential. The actual functional form of these distributions is presently under investigation.

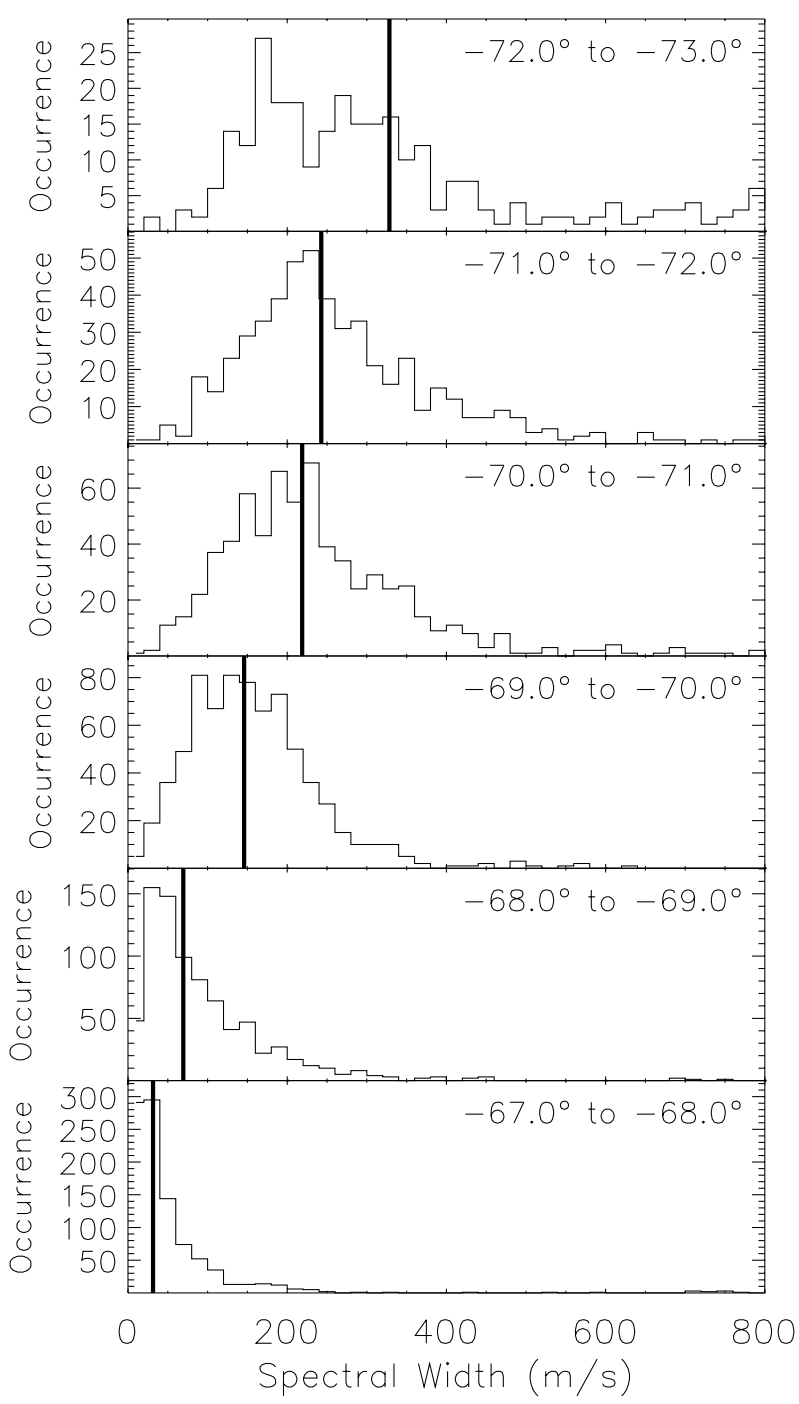

Fig. 5. The distributions of spectral width from all beams of the Halley radar measured during the interval 14:48-15:15 UT (interval C) on 14 August 1998. The distributions have been split into $1^{\circ}$ latitude bins from $-67^{\circ}$ to $-73^{\circ}$. The bold vertical lines represent the medians of each distribution.

Figure 3 further illustrates that the transition between the two spectral width regions in interval A is very sharp and the amplitude of the change is large. The four spectral width threshold values are located between the median values of the above and below boundary distributions and the transition from one region to the other occurs over less than $1^{\circ}$ of latitude, resulting in identical boundary estimations when using the different threshold values. Hence we have a large degree of confidence that we have identified the SWB location with an uncertainty $\sim 1$ range gate $(45 \mathrm{~km})$.

Figure 4 presents the spectral width values for interval B for the geomagnetic latitude range $-68^{\circ}$ to $-74^{\circ}$, separated into $1^{\circ}$ latitude bins. Again, the low-latitude distribution can be described as exponential, and the high-latitude distribution as Gaussian. Whereas the beam 4 data presented in Fig. 2 has a data gap between $-69^{\circ}$ and $-72^{\circ}$, some of the 
other Halley beams observe backscatter within this region, hence the distributions in this region in Fig. 4. Although these distributions suggest a transition exists between $\sim-70^{\circ}$ and $\sim-72^{\circ}$, the lack of data in the beam 4 data set means that it is impossible to estimate a boundary location using data from this beam alone.

Figure 5 presents the distributions of the spectral width values for interval $\mathrm{C}$ for the geomagnetic latitude range $-67^{\circ}$ to $-73^{\circ}$, separated into $1^{\circ}$ latitude bins. The variation in the distributions presented here is very different to the previous intervals. At the lowest latitude we still see the exponential distribution, and at the highest latitude we still see the Gaussian distribution. However, the gradient of the latitudinal transition between the two regions is not as sharp as in interval $\mathrm{A}$ and the amplitude of the change between the low and high-latitude distributions is much reduced. It is most likely that this scenario matches that presented in Fig. 1c. This explains the variable locations of the boundary identifications when applying the different spectral width threshold values to the data.

\section{Magnetic Local Time Differences in Spectral Width Distributions}

The example presented above illustrates the variety of spectral width transitions that may be observed and how the application of multiple thresholds may be used to probe their structure. We now perform a statistical study to investigate how these spectral width transitions differ at different MLTs. Previous statistical studies of this type (André et al., 2002; Hosokawa et al., 2002; Villain et al., 2002; Woodfield et al., 2002c) have presented spectral width distribution characteristics in a fixed geomagnetic coordinate reference frame. Because the latitude of the boundary location varies with time, this method of presentation intermixes the spectral width distributions from different geophysical regions close to the average boundary location i.e., the above and below boundary distributions are intermixed for a wide range of latitudes. This reduces the sharpness of the transitions in the statistical picture. In this study, we compile the spectral width distributions at all MLTs with respect to the locations of the actual latitudinal spectral width transitions (rather than with latitude, as in the studies cited above). The C-F threshold technique was applied to five year's worth of spectral width data (from 1997 to 2001 inclusive) from the meridional beam (beam 8) of the Halley SuperDARN radar. The statistics were compiled in the following way:

1. We used common mode data only. This ensured that the radar was running exactly the same program for all the intervals in the database and that the processing of the data was consistent.

2. The raw data were processed using the same version of the SuperDARN data processing software.

3. Data flagged as ground backscatter during the raw data processing were removed; ground backscatter is typ-

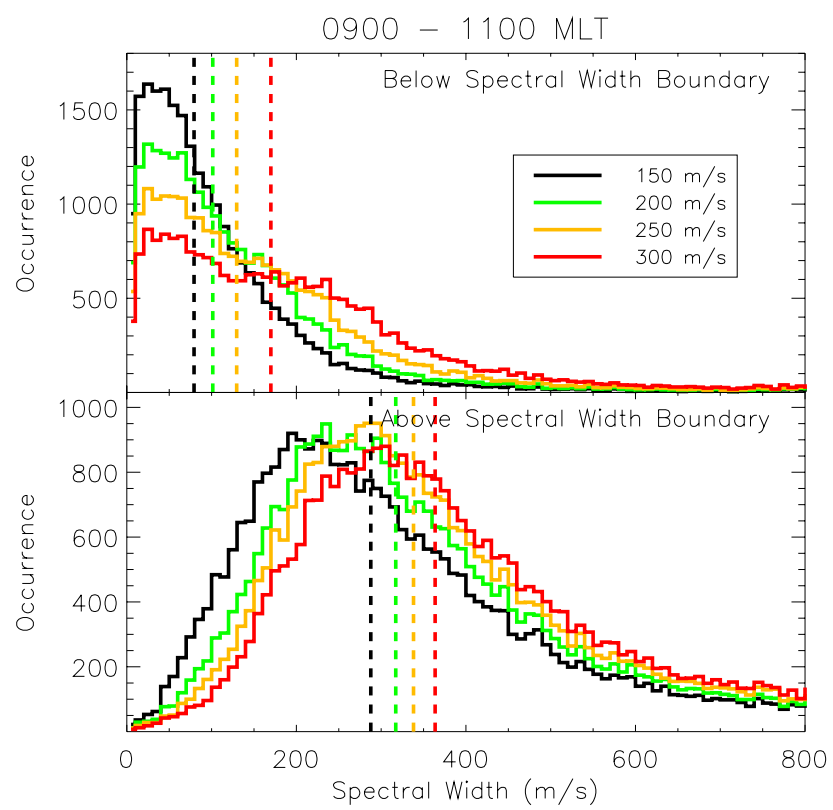

Fig. 6. The distribution of spectral width values below (equatorward of) and above (poleward of) the spectral width boundary determined by applying the C-F threshold technique to 5-years worth of spectral width data from beam 8 of the Halley SuperDARN radar. Only data from the 09:00-11:00 MLT region, and from within 10 range gates of the estimated boundary location, are shown. The four different histograms represent the results from using four different spectral width threshold values $(150,200,250$, and $300 \mathrm{~m} / \mathrm{s})$ to identify the boundary.

ically characterised by low Doppler velocity and low Doppler spectral width (Chisham and Pinnock, 2002).

4. E-region backscatter at low ranges $(<$ range gate 10$)$ was removed.

5. Backscatter with a signal power of less than $3 \mathrm{~dB}$ was removed.

6. The C-F threshold technique was applied blindly to the complete 5-year data set using multiple spectral width thresholds.

Although statistical distributions were determined for all MLTs, we choose to focus initially on two contrasting 2-h MLT regions: the 09:00-11:00 MLT sector (which typifies the cusp region), and the 15:00-17:00 MLT sector (which typifies the afternoon sector). Statistical studies of the spectral width transitions in these regions will help the understanding of the diverse nature of the transitions at different MLTs.

We focus first on the 09:00-11:00 MLT sector, which we have chosen as being representative of the cusp region. In Fig. 6 we present the distributions of the spectral width values observed below (equatorward) and above (poleward) of the SWB when applying the technique with four spectral width threshold values $(150,200,250$, and $300 \mathrm{~m} / \mathrm{s})$. Only the spectral width values from within 10 range gates 

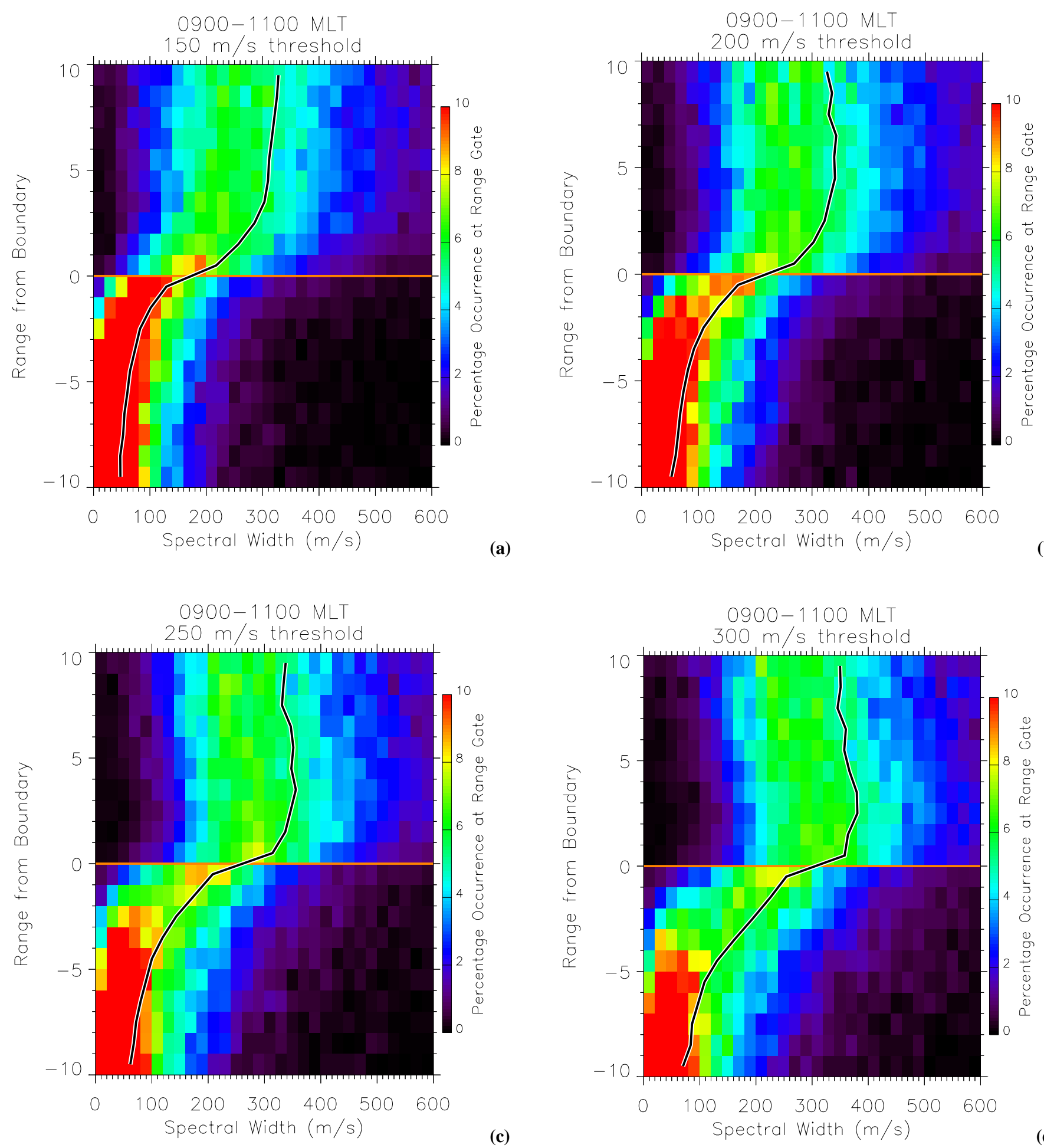

(b)

(d)

Fig. 7. The distribution of spectral width values ordered by range from the spectral width boundary, determined by applying the C-F threshold technique to 5-years worth of spectral width data from beam 8 of the Halley SuperDARN radar. Only data from the 09:00-11:00 MLT region are shown. The results are presented for four different spectral width threshold values, (a) $150 \mathrm{~m} / \mathrm{s}$, (b) $200 \mathrm{~m} / \mathrm{s}$, (c) $250 \mathrm{~m} / \mathrm{s}$, and (d) $300 \mathrm{~m} / \mathrm{s}$. The horizontal orange line represents the boundary location. The black on white lines represent the variations of the medians of the distributions with range from the boundary. 
$(450 \mathrm{~km})$ of the estimated boundary location were used in the compilation of these distributions. These distributions are very similar to those determined by Chisham and Freeman (2003) (see their Fig. 15); their database comprised one year's worth of Halley data from the 08:00-12:00 MLT range. These distributions represent the best approximations to those found in the cusp (above boundary) and sub-cusp (below boundary) regions. However, the fact that the distributions for different thresholds are not identical suggests that they do not always identify the boundary at the same range gate (this is the case even for relatively sharp boundaries, as shown in the earlier example).

In order to study the statistical nature of the transition in this MLT range we now examine the variation in the spectral width distributions with distance from the estimated boundary location. In Fig. 7 we present four contour plots, one for each of the threshold values employed, $150 \mathrm{~m} / \mathrm{s}$ (Fig. 7a), $200 \mathrm{~m} / \mathrm{s}$ (Fig. 7b), $250 \mathrm{~m} / \mathrm{s}$ (Fig. 7c), and $300 \mathrm{~m} / \mathrm{s} \mathrm{(Fig.} \mathrm{7d).}$ The figures illustrate the spatial variations in the spectral width distribution relative to the estimated boundary location (range 0 in Fig. 7), up to a maximum of 10 range gates above, and below, the boundary. The distribution at each relative range gate has been normalised using the total number of spectral width values measured at that location. The horizontal (orange) line in each plot represents the estimated boundary location. The black on white bold line represents the variation of the median of the distribution with distance from the boundary. This method of presentation of the spectral width distributions is similar to that used by Hosokawa et al. (2002) and Woodfield et al. (2002c). However, whereas their statistical distributions were ordered by geomagnetic latitude and the transition consequently smoothed, this ordering by distance to the estimated boundary location illustrates better the statistical structure of the transition.

Figure 7a presents the spectral width distributions when a threshold value of $150 \mathrm{~m} / \mathrm{s}$ is applied to the data. More than three range gates poleward of the boundary the distributions are very similar with a median value $\sim 300-330 \mathrm{~m} / \mathrm{s}$. Similarly, more than three range gates equatorward of the boundary the distributions are very similar with a median value $\sim 50-80 \mathrm{~m} / \mathrm{s}$. This illustrates the large amplitude of the change between the distributions that we typically see within, and equatorward of, the cusp region. However, the region in between (from -3 to +3 range gates) represents a region of transition where the distribution is changing gradually from the below boundary to the above boundary distribution. The sharpest change occurs at the observed boundary location where the median value changes from $\sim 130$ to $\sim 220 \mathrm{~m} / \mathrm{s}$. Hence, the transition in this MLT region occurs statistically over $\sim 6$ range gates. As we increase the value of the threshold employed (see Figs. 7b-d) then we see that the boundary determination is placed increasingly at the higher latitude end of this transition, culminating in Fig. $7 \mathrm{~d}(300 \mathrm{~m} / \mathrm{s})$ where the spectral width transition occurs wholly equatorward of the estimated boundary location.

We now focus on studying the distributions in the 15:0017:00 MLT sector. In Fig. 8 we present the distributions of

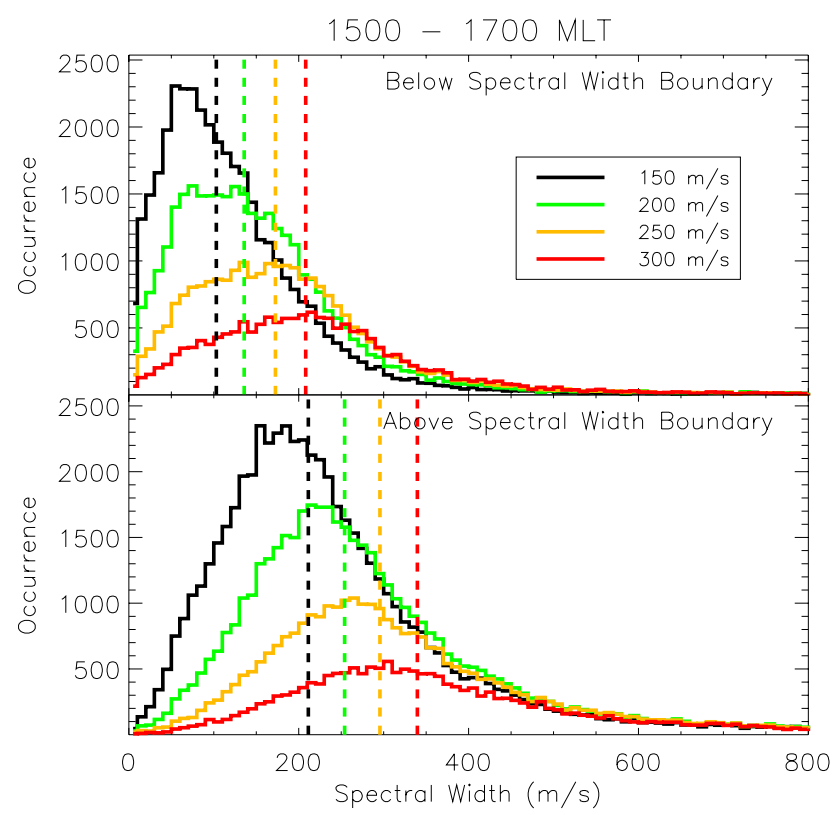

Fig. 8. The distribution of spectral width values below (equatorward of) and above (poleward of) the spectral width boundary determined by applying the C-F threshold technique to 5-years worth of spectral width data from beam 8 of the Halley SuperDARN radar. Only data from the 15:00-17:00 MLT region, and from within 10 range gates of the estimated boundary location, are shown. The four different histograms represent the results from using four different spectral width threshold values $(150,200,250$, and $300 \mathrm{~m} / \mathrm{s})$ to identify the boundary.

the spectral width values observed below (equatorward) and above (poleward) the SWB when applying our standard four spectral width thresholds. The distributions have been compiled in the same way as in Fig. 6. The major difference between this MLT sector and the 09:00-11:00 MLT sector is that we do not understand how the observed latitudinal transitions in spectral width relate to the PCB, or to any other ionospheric projections of the magnetospheric system. However, we still identify latitudinal transitions in spectral width in this MLT region. One of the major differences between the distributions presented in Fig. 8 and those measured in the 09:00-11:00 MLT sector (as presented in Fig. 6) is the reduction in the size of the distributions (area under the histograms) with increasing threshold value. This is a result of decreasing numbers of boundaries being identified by the technique as the threshold value is increased.

In order to study why this is the case, we present, in Fig. 9, contour plots of the spatial variations in the spectral width distributions relative to the estimated boundary location (as was done for the 09:00-11:00 MLT sector in Fig. 7). Figure $9 \mathrm{a}$ presents the spectral width variations when a threshold value of $150 \mathrm{~m} / \mathrm{s}$ is employed. Whereas the data presented in Fig. 7a showed the presence of a transition across $\sim 6$ range gates, this figure suggests that, statistically, a sharper SWB transition occurs in this MLT range (the size of the jump at the observed boundary is a larger percentage of the 

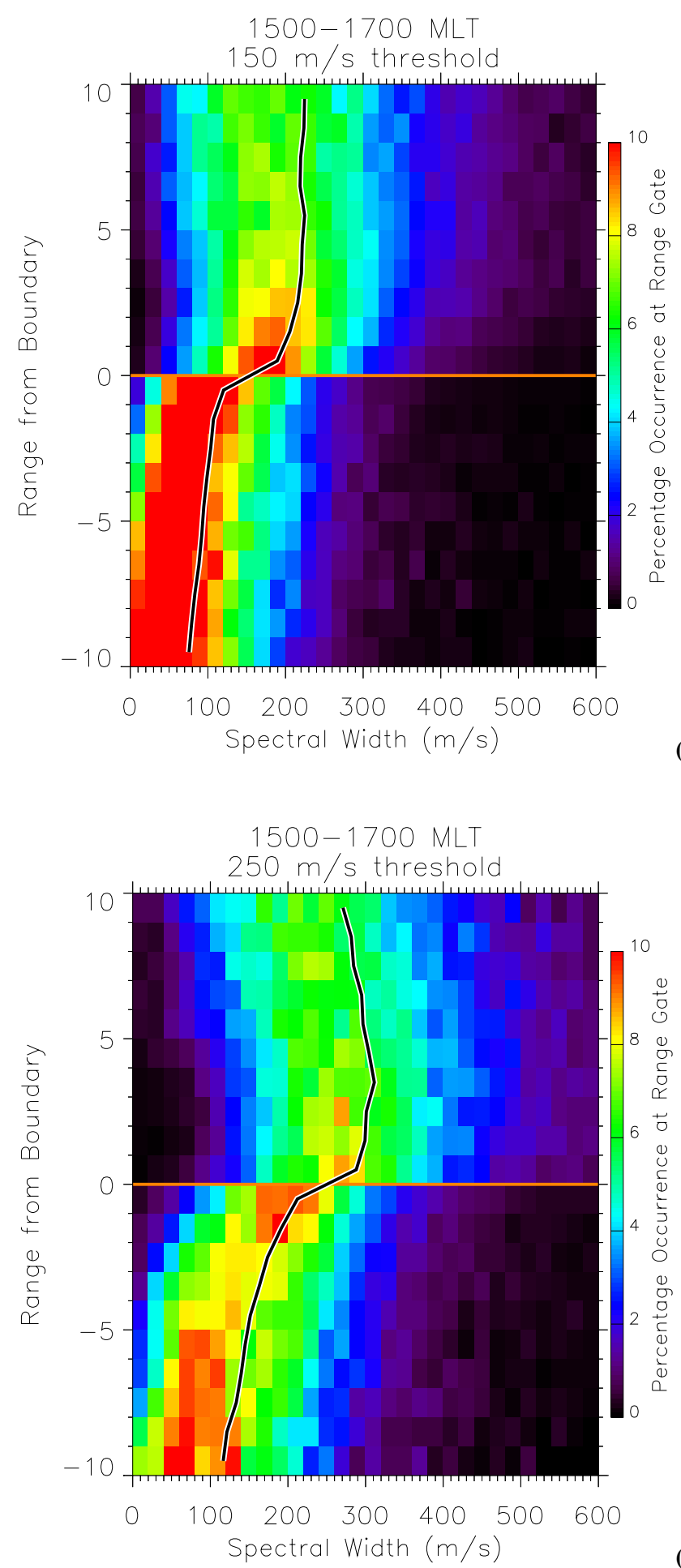

(a)

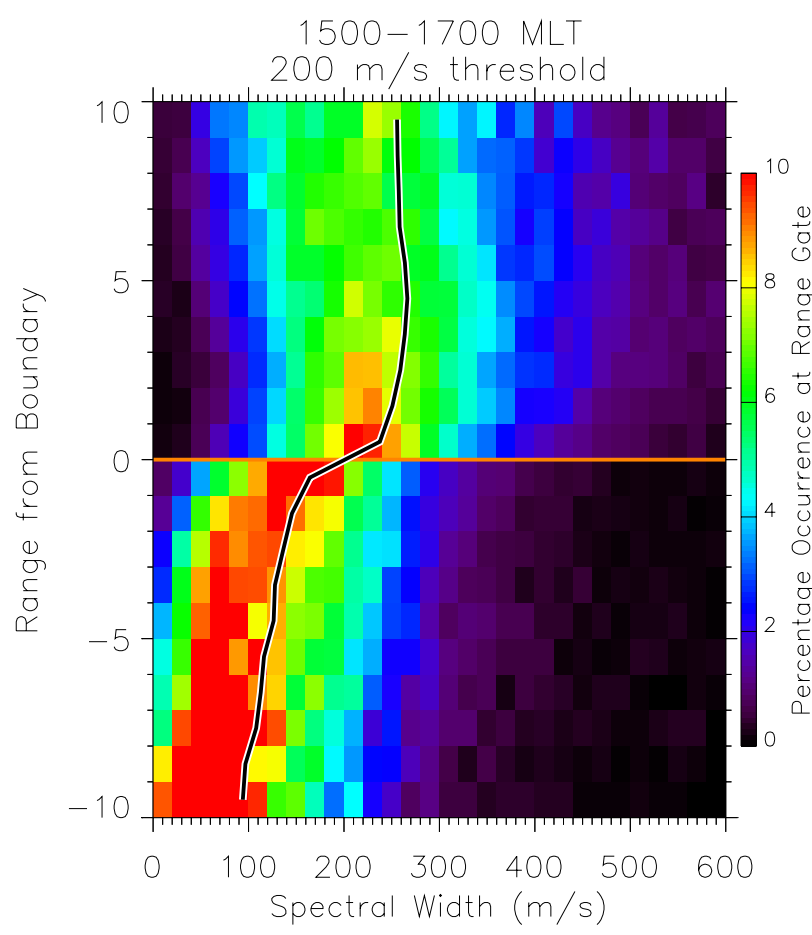

(b)

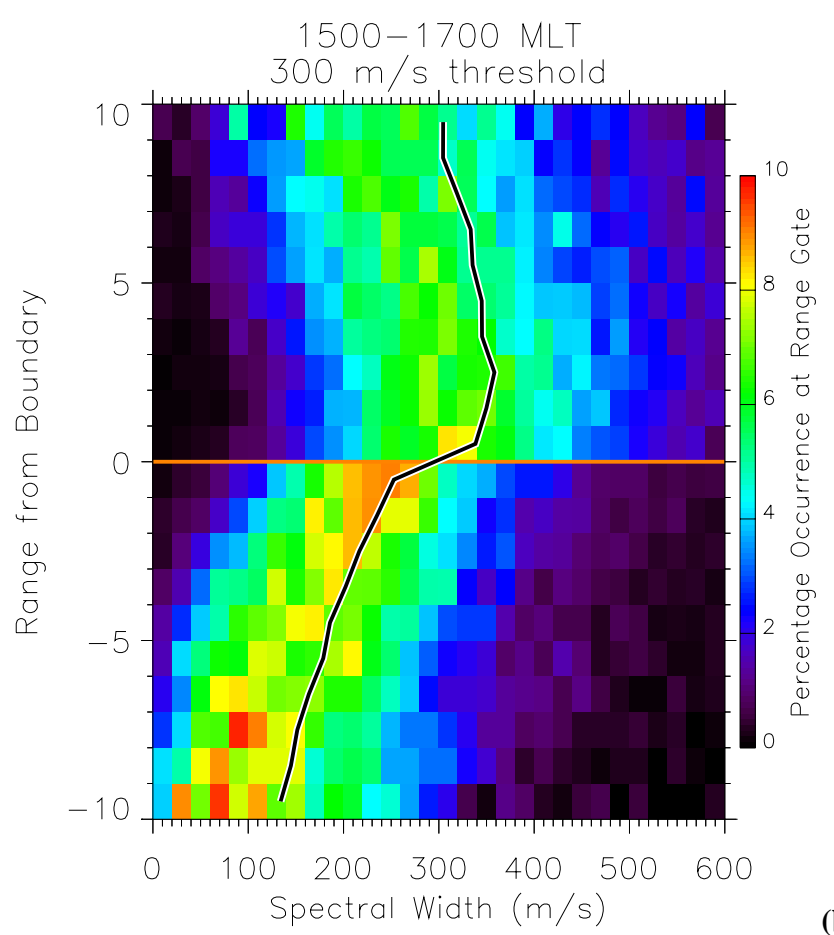

(b)

Fig. 9. The distribution of spectral width values ordered by range from the spectral width boundary, determined by applying the C-F threshold technique to 5-years worth of spectral width data from beam 8 of the Halley SuperDARN radar. Only data from the 15:00-17:00 MLT region are shown. The results are presented for four different spectral width threshold values, (a) $150 \mathrm{~m} / \mathrm{s}$, (b) $200 \mathrm{~m} / \mathrm{s}$, (c) $250 \mathrm{~m} / \mathrm{s}$, and (d) $300 \mathrm{~m} / \mathrm{s}$. The horizontal orange line represents the boundary location. The black on white lines represent the variations of the medians of the distributions with range from the boundary. 
overall transition). More than 1 range gate poleward of the boundary the distributions are very similar with a median value $\sim 190-230 \mathrm{~m} / \mathrm{s}$. More than 1 range gate equatorward of the boundary the distributions are also very similar with a median value $\sim 70-120 \mathrm{~m} / \mathrm{s}$. Hence, another major difference between these distributions and those seen in the 09:00-11:00 MLT sector is that the amplitude of the change between the above and below boundary distributions is much less. The difference between the above and below-boundary distribution medians here is $\sim 80-140 \mathrm{~m} / \mathrm{s}$ as compared to a difference of $\sim 220-280 \mathrm{~m} / \mathrm{s}$ in the 09:00-11:00 MLT sector. This reduction in amplitude means that it is more difficult to distinguish between spectral width data from above and below the boundary. The scenario is very similar to that presented in Fig. 1c, where the transition is sharp but the amplitude of the transition between the spectral width distributions is small. In this case, the application of threshold values greater than $\sim 200 \mathrm{~m} / \mathrm{s}$ would seem to be inappropriate for accurately identifying the location of the transition.

This observation explains the reduction in the number of transitions observed (and hence, the reduction in the area underneath the distribution curves) with increasing threshold value. For threshold values greater than the median of the above-boundary distribution (i.e. thresholds $>\sim 200 \mathrm{~m} / \mathrm{s}$ in this case), the likelihood of satisfying the algorithm criteria is low if the spectral width values are independent and identically distributed. The likelihood could be higher only if large spectral width values tend to be grouped in space or if the median of the above-boundary distribution from an individual radar scan is sometimes greater than the median of the distribution for all radar scans. Figures $9 b-d$ suggest that the latter does occur in a limited amount of cases. These observations suggest that lower threshold values (in the range $100-200 \mathrm{~m} / \mathrm{s}$ ) are appropriate for an accurate boundary determination in this MLT sector.

In Fig. 10, we present the variation of the median spectral width with respect to the estimated boundary location, across the full $24 \mathrm{~h}$ of MLT, when using a spectral width threshold value of $150 \mathrm{~m} / \mathrm{s}$ (as in Figs. 7a and 9a). This illustrates the statistical nature of the transition at all MLTs. The cusp region is clearly visible (centred around 09:00-11:00 MLT), characterised by a large amplitude change between the above and below boundary distributions. However, the gradient of the statistical boundary varies with MLT. Another region where a large amplitude change exists is on the nightside (centred on 01:00-03:00 MLT), although in this case the statistical transition is more shallow. The MLT variations on the nightside agree with the observations of Woodfield et al. (2002c) who showed that, in the nightside ionosphere, broader spectral widths were observed after 22:00 MLT, and into the early morning sector. In the afternoon sector, the change in amplitude between the above and below-boundary distributions is very low (as was illustrated in Figs. 8 and 9), although the transition between these two regions appears to have a sharp gradient (i.e. it occurs almost wholly at the boundary location).

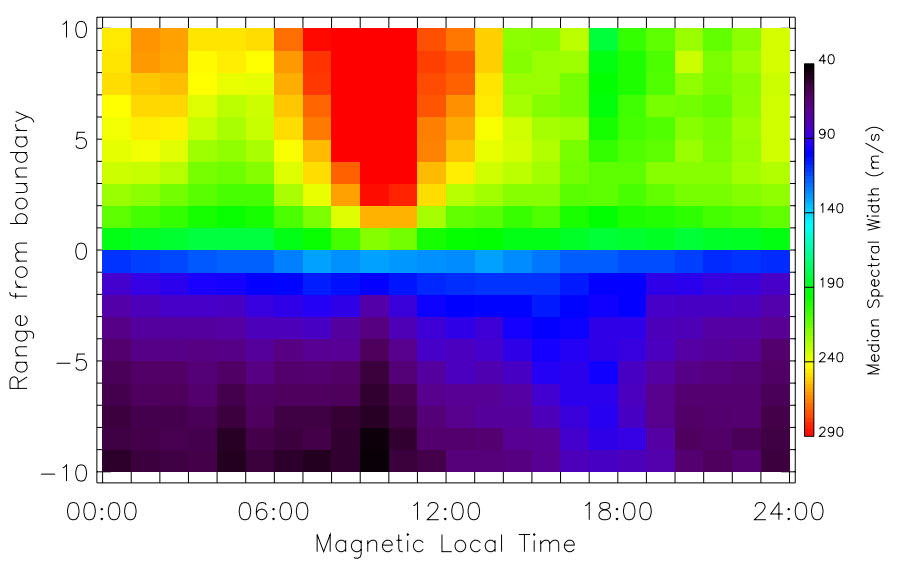

Fig. 10. The variation of median spectral width with MLT and range from the boundary.

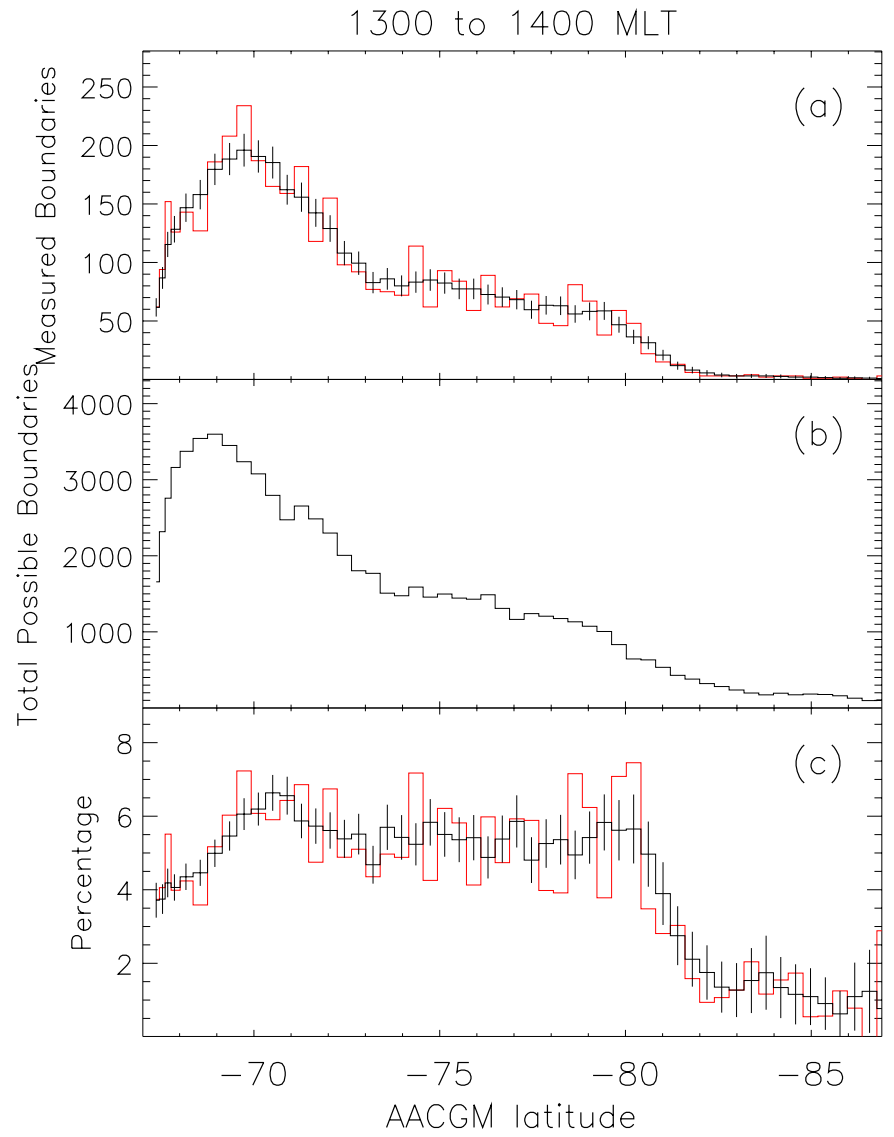

Fig. 11. The latitudinal variation of different boundary location statistics in the 13:00-14:00 MLT range: (a) The aggregate occurrence distribution of observed boundary locations (red), and the same distribution smoothed by the application of a 5-range gate moving average (black). (b) The aggregate occurrence distribution of the total number of possible boundary identifications. (c) The probability distribution of observed boundary locations (red), and the smoothed probability distribution of observed boundary locations (black). 


\section{Magnetic Local Time Distribution of Boundary Loca- tions}

In this section we take a look at the statistical distribution of the boundary locations determined from applying the C$\mathrm{F}$ threshold technique to the 5-year Halley database. Here, we only show the results obtained when applying a spectral width threshold value of $150 \mathrm{~m} / \mathrm{s}$ (this threshold appears best applicable for the complete 24-h MLT range). We determine the probability distribution of boundary locations as follows:

1. We determine the aggregate occurrence distribution of measured boundary locations binned latitudinally by range gate and separated into 1 -h wide MLT bins. In Fig. 11a we present the distribution observed in a single MLT sector (13:00-14:00 MLT). The red histogram presents the observed variation of the total occurrence of measured boundaries. Although showing clear trends with latitude, there is often a large range-to-range variability. There are a number of instances where we observe a suddenly enhanced number of measured boundaries at one latitude followed immediately by a drop in the number of boundaries at the next. This is almost certainly an instrumental effect in the Halley radar data, probably due to the occurrence of less good autocorrelation functions at certain range gates due to aspects of the radar pulse pattern. These often result in enhanced spectral width values which would lead to a slightly enhanced number of boundary determinations at these range gates followed by a slight dropout in boundary determinations at the next range gate. This is clearly apparent (at nearly all MLTs) for range gate 23 which is located at $\sim-71.3^{\circ}$ AACGM latitude. In order to reduce the impact of these instrumental effects we have determined a 5-range gate moving average of the number of measured boundaries. This is presented as the black histogram in Fig. 11a. The error bars on this histogram represent the statistical uncertainty in the measurements. The smoothed histogram is clearly peaked around $\sim-70^{\circ}$ latitude in this MLT range.

2. We normalise the aggregate occurrence distribution at all range gates and MLTs by dividing by the occurrence distribution of the total number of possible boundaries that could have been measured at each location, for the complete 5-year data set. A boundary can potentially be identified at a location if 5 range gates with good spectral width data exist within a series of 7 consecutive range gates (see steps (4) and (5) in section 2). Figure $11 \mathrm{~b}$ presents the latitudinal variation of the total number of possible boundary identifications in the 13:00-14:00 MLT sector. The spatial variation is very similar to that in Fig. 11a, being peaked around $\sim-69^{\circ}$ latitude.
3. The normalisation results in the true probability distribution of observed boundary locations. Figure 11c presents this probability distribution for the 13:00 14:00 MLT sector, the red histogram representing the true observed variation, and the black histogram representing the smoothed variation. This clearly shows the effects of the normalisation of the distribution; the peak around $\sim-70^{\circ}$ has been removed and the probability distribution is approximately flat across a large latitude range (from $\sim-69^{\circ}$ to $-80^{\circ}$ ).

In Fig. 12 we present the smoothed probability distribution extended to all MLTs. Boundaries are at least three times as likely to be located in the red-shaded regions as in the blue. The most clearly-defined preferred boundary locations are in the cusp/late-morning sector where the peak occurrence (at $\sim-74^{\circ}$ ) is bordered at both low and high latitudes by regions of very low occurrence. The peak in occurrence forms a continuous line through the early morning sector and into the nightside, where the peak region extends from $\sim-72^{\circ}$ to $\sim-67^{\circ}$ (the equatorward edge of our field of view). In actuality it may extend to even lower latitudes on the nightside. This continuous line of peak occurrence continues round to $\sim$ 18:00 MLT. Between $\sim 12: 00$ and $\sim 18: 00$ MLT there appears to be less order to the statistics and the picture is characterised by multiple occurrence peaks with latitude. It may be that lower spectral width thresholds need to be applied to identify the SWB clearly in this sector. However, it may be that there are physical factors which preclude the observation of a more consistent boundary location in this sector. An interesting feature in the noon sector (from $\sim 11: 00$ to 14:00 MLT) is the occurrence of a preferred boundary region at high latitudes around $\sim-80^{\circ}$. It is possible that these boundaries relate to measurements made under northward IMF conditions.

\section{Discussion}

In this paper we have investigated the application of the $\mathrm{C}-\mathrm{F}$ threshold technique to the determination of latitudinal transitions in SuperDARN spectral width data sets. Both the example event and the statistical results have shown that, if an accurate determination is required, inspection of the spectral width distributions is crucial in order to determine the optimum spectral width thresholds that need to be used when applying the technique. The results presented here have shown that rarely can a transition be fully investigated by the application of an algorithm with a single spectral width threshold, as most studies tend to assume. Using a single threshold value implies that we are assuming that our boundary is wellapproximated by an infinitely sharp transition. By application of the C-F threshold technique with multiple threshold values, we have shown how it is possible to estimate the uncertainty in the boundary location, which can alternatively be viewed as a measure of the thickness of the boundary transition. 


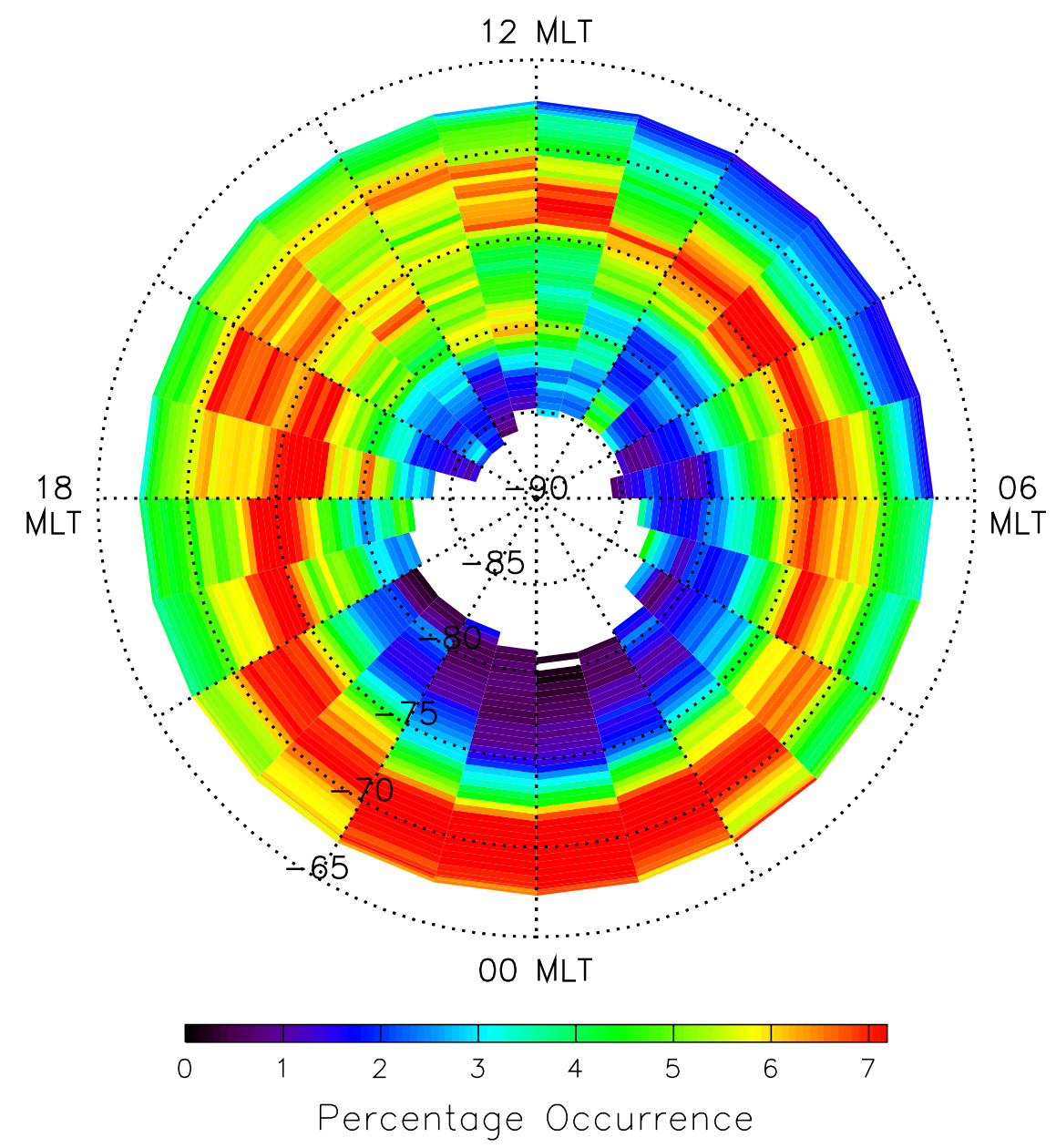

Fig. 12. The probability distribution of observed boundary locations determined within the 5-year Halley database using the C-F threshold technique, smoothed by the application of a 5-range gate moving average.

We have shown that the statistical boundary transition observed in the 09:00-11:00 MLT sector (as presented in Fig. 7) extended across $\sim 6$ range gates. This observation could be explained in a number of ways:

(1) The typical boundary transition in this MLT range occurs across $\sim 4-6$ range gates $\left(\sim 1.5-2.5^{\circ}\right.$ of latitude) and the sharper boundary presented in our example (Figs. 2 and 3 ) is an exception to the norm.

(2) Mixing results from all geomagnetic conditions has smeared the statistical transition and it may be sharper under specific IMF/solar wind conditions (e.g., at times of prevailing southward IMF). Woodfield et al. (2002c) showed the large effect that season has on spectral width and mixing data from all seasons may also have affected the distribution of boundary locations that we have observed.

(3) A lot of boundary motion is expected in the cusp region due to the effects of reconnection. The use of temporal median filtering may have smeared the statistical boundary location if these boundary motions are rapid and often.

The thickness of these transitions requires further study, including subdividing the data by the prevailing IMF and seasonal conditions. Further studies will attempt to clarify the changes in the spectral width distributions in response to changes in the IMF conditions. It will also be interesting to study the finite thickness of the transition in comparison with other data sets to determine how aspects of the transition relate to the ionospheric projections of the central plasma sheet (CPS), the low-latitude boundary layer (LLBL), the cusp and the mantle, as defined by the particle precipitation regions regularly observed by low-altitude spacecraft (Newell and Meng, 1992, 1994).

The 24-h MLT statistics have shown that the spectral width distributions, and their means and medians, vary considerably with both latitude and MLT. Hence, the spectral width thresholds employed when applying the technique must be adjusted to suit the transitions typically observed in each MLT region. However, although SWBs can often be identified at all MLTs using this technique, how these boundaries relate to geophysical boundaries in the magnetospheric system away from the cusp region is still unclear. The picture is particularly complex in the 12:00-18:00 MLT sector. Further work continues on correlating SWBs with independent observations from other instrumentation e.g. precipitation boundaries observed by low-altitude spacecraft. 
The observation of a clearly preferred boundary location (presented in Fig. 12) that is continuous from noon (12:00 MLT), through the morning sector and the nightside, to $\sim 18: 00 \mathrm{MLT}$, is very interesting. It suggests that this SWB represents the PCB, as this is known to be what it represents in the cusp. A large-scale comparison of the boundaries determined here with those identified in other independent data sets should resolve this question.

This study has presented statistical distributions of spectral width data from the Halley SuperDARN radar only. Different SuperDARN radars often show different spectral width probability distributions, at the same geomagnetic locations, due mainly to the orientation of their fields-of-view and their geographic location. Although the spectral width distributions are generally of the same functional form, the MLT variation of the medians of the distributions varies for different radars. Some of the factors which result in these differences between radars are still poorly understood. Because of these differences, changes to the technique (specifically the spectral width thresholds that are applied) are needed to address these differences when trying to locate a SWB. Hence, no presumption should be made about the best threshold values to apply. It is also the case that, in the cusp region, some radars rarely measure a below-boundary distribution, and as a result, in many studies the equatorward edge of the cusp backscatter is taken as a proxy for the PCB. Although case studies have shown that this backscatter boundary compares favourably with the PCB identified by other techniques (Milan et al., 1999), there is still a question mark concerning its reliability as a PCB proxy, as was discussed earlier in this paper. It needs to be proved statistically (again by comparison with other independent data sets) that this represents a reliable proxy for the PCB.

In this study we have restricted our analysis to the use of meridional radar beams or those aligned close to the meridional direction. The meridional beam tends to most clearly show any SWB transitions that exist in the data set. It is important to understand variations which might occur due to variations in the direction of the radar beam being used in the analysis. For beams which are directed some distance from the meridional direction there are often potential sources of high spectral width which are uncorrelated with the footprints of specific magnetospheric regions (Villain et al., 2002). This must be a consideration in the interpretation of high spectral width values in studies which have employed radar beams far from the meridional direction (Hosokawa et al., 2002; Woodfield et al., 2002c). Work in progress with a number of SuperDARN radars (not shown) suggests that beams directed within $30^{\circ}$ of the meridional direction are most suitable for observing the SWB.

To summarise, in order to fully understand the variations in spectral width in the high-latitude ionosphere, and to be able to use these characteristics routinely to study magnetospheric dynamics, the following questions need to be addressed:
1. For what range of MLT does the SWB represent the $\mathrm{PCB}$, and what does it represent at other MLTs?

2. How do spectral width distributions change with the specific characteristics of each radar? (e.g. with the orientation of beams, with the location of fields of view, and with the modes of operation).

3. How do spectral width characteristics relate to the PCB and other boundaries (in the cusp and elsewhere) under northward IMF conditions?

These questions are presently under investigation.

\section{Conclusions}

In this paper we have determined the probability of observing a latitudinal spectral width transition as a function of latitude and MLT. We conclude that:

1. Latitudinal spectral width transitions can be observed at any MLT.

2. The gradient and amplitude of these transitions changes with MLT. High amplitude and high gradient transitions are seen in the cusp. High amplitude and low gradient transitions are seen on the nightside. Low amplitude and high gradient transitions are seen in the afternoon sector.

3. For this reason, the transitions are well-defined in the cusp, morning, and nightside sectors forming a continuous ring. These observations suggest that these transitions may relate to the PCB, as this is known to be what they relate to in the cusp region. However, the transitions are ill-defined in the afternoon sector.

Acknowledgements. We are extremely grateful for helpful discussions with, and suggestions by, M. Pinnock. We are grateful to R. Hibbins, N. Edwards, and T. Trypiniotis for database and software assistance. The Halley radar was developed under funding from the NERC(UK) and the NSF(US). Operations are supported by the NERC(UK).

Topical Editor M. Lester thanks E. Woodfield and M. L. Parkinson for their help in evaluating this paper.

\section{References}

André, R., Pinnock, M., and Rodger, A. S.: On the SuperDARN autocorrelation function observed in the ionospheric cusp, Geophys. Res. Lett., 26, 3353-3356, 1999.

André, R., Pinnock, M., and Rodger, A. S.: Identification of the low-altitude cusp by Super Dual Auroral Radar Network radars: A physical explanation for the empirically derived signature, J. Geophys. Res., 105, 27 081-27 093, 2000a. 
André, R., Pinnock, M., Villain, J.-P., and Hanuise, C.: On the factors conditioning the Doppler spectral width determined from SuperDARN HF radars, Int. J. Geomagn. Aeron., 2, 77-86, 2000 b.

André, R., Pinnock, M., Villain, J.-P., and Hanuise, C.: Influence of magnetospheric processes on winter $\mathrm{HF}$ radar spectra characteristics, Ann. Geophys., 20, 1783-1793, 2002.

Baker, K. B., Dudeney, J. R., Greenwald, R. A., Pinnock, M., Newell, P. T., Rodger, A. S., Mattin, N., and Meng, C.-I.: HF radar signatures of the cusp and low-latitude boundary layer, J. Geophys. Res., 100, 7671-7695, 1995.

Baker, K. B., Rodger, A. S., and Lu, G.: HF-radar observations of the dayside magnetic merging rate: A Geospace Environment Modeling boundary layer campaign study, J. Geophys. Res., 102, 9603-9617, 1997.

Blanchard, G. T., Lyons, L. R., Samson, J. C., and Rich, F. J.: Locating the polar cap boundary from observations of $6300 \AA$ auroral emission, J. Geophys. Res., 100, 7855-7862, 1995.

Blanchard, G. T., Lyons, L. R., de la Beaujardière, O., Doe, R. A., and Mendillo, M.: Measurement of the magnetotail reconnection rate, J. Geophys. Res., 101, 15265-15276, 1996.

Blanchard, G. T., Lyons, L. R., and Samson, J. C.: Accuracy of using $6300 \AA$ auroral emission to identify the magnetic separatrix on the nightside of the earth, J. Geophys. Res., 102, 9697-9703, 1997.

Blanchard, G. T., Ellington, C. L., Lyons, L. R., and Rich, F. J.: Incoherent scatter radar identification of the dayside magnetic separatrix and measurement of magnetic reconnection, J. Geophys. Res., 106, 8185-8195, 2001.

Chisham, G., and Freeman, M. P.: A technique for accurately determining the cusp-region polar cap boundary using SuperDARN HF radar measurements, Ann. Geophys., 21, 983-996, 2003.

Chisham, G., and Pinnock, M.: Assessing the contamination of SuperDARN global convection maps by non-F-region backscatter, Ann. Geophys., 20, 13-28, 2002.

Chisham, G., Pinnock, M., and Rodger, A. S.: The response of the HF radar spectral width boundary to a switch in the IMF $B_{y}$ direction: Ionospheric consequences of transient dayside reconnection? J. Geophys. Res., 106, 191-202, 2001.

Chisham, G., Pinnock, M., Coleman, I. J., Hairston, M. R., and Walker, A. D. M.: An unusual geometry of the ionospheric signature of the cusp: Implications for magnetopause merging sites, Ann. Geophys., 20, 29-40, 2002.

de la Beaujardière, O., Lyons, L. R., Ruohoniemi, J. M., FriisChristensen, E., Danielsen, C., Rich, F. J., and Newell, P. T.: Quiet-time intensifications along the poleward auroral boundary near midnight, J. Geophys. Res., 99, 287-298, 1994.

Dudeney, J. R., Rodger, A. S., Freeman, M. P., Pickett, J., Scudder, J., Sofko, G., and Lester, M.: The nightside ionospheric response to IMF $B_{y}$ changes, Geophys. Res. Lett., 25, 2601-2604, 1998.

Evans, L. C., and Stone, E. C.: Electron polar cap and the boundary of open geomagnetic field lines, J. Geophys. Res., 77, 5580$5585,1972$.

Greenwald, R. A., Baker, K. B., Dudeney, J. R., Pinnock, M., Jones, T. B., Thomas, E. C., Villain, J.-P., Cerisier, J.-C., Senior, C., Hanuise, C., Hunsucker, R. D., Sofko, G., Koehler, J., Nielsen, E., Pellinen, R., Walker, A. D. M., Sato, N., and Yamagishi, H.: DARN/SuperDARN: A global view of the dynamics of highlatitude convection, Space Sci. Rev., 71, 761-796, 1995.

Gurnett, D. A.: Auroral plasma waves, in Auroral physics, Eds. Meng, C.-I., Rycroft, M. J., and Franck, L. A., Cambridge Univ. Press, New York, Ch. IV-6, pp. 241-254, 1991.
Hosokawa, K., Woodfield, E. E., Lester, M., Milan, S. E., Sato, N., Yukimatu, A. S., and Iyemori, T.: Statistical characteristics of Doppler spectral width as observed by the conjugate SuperDARN radars, Ann. Geophys., 20, 1213-1223, 2002.

Huber, M., and Sofko, G. J.: Small-scale vortices in the highlatitude F region, J. Geophys. Res., 105, 20 885-20 897, 2000.

Khan, H., Lester, M., Davies, J. A., Milan, S. E., and Sandholt, P. E.: Multi-instrument study of the dynamic cusp during dominant IMF $B_{y}$ conditions, Ann. Geophys., 21, 693-708, 2003.

Lester, M., Milan, S. E., Besser, V., and Smith, R.: A case study of $\mathrm{HF}$ radar spectra and $630.0 \mathrm{~nm}$ auroral emission in the premidnight sector, Ann. Geophys., 19, 327-339, 2001.

Lockwood, M., Carlson, H. C., and Sandholt, P. E.: The implications of the altitude of transient $630 \mathrm{~nm}$ dayside auroral emission, J. Geophys. Res., 98, 15571-15587, 1993.

Matsuoka, A., Tsuruda, K., Hayakawa, H., Mukai, T., Nishida, A., Okada, T., Kaya, N., and Fukunishi, H.,: Electric field fluctuations and charged particle precipitation in the cusp, J. Geophys. Res., 98, 11225-11234, 1993.

Maynard, N. C., Aggson, T. L., Basinka, E. M., Burke, W. J., Craven, P., Peterson, W. K., Suguira, M., and Weimer, D. R.: Magnetospheric boundary dynamics: DE-1 and DE-2 observations near the magnetopause and cusp, J. Geophys. Res., 96, 3505-3522, 1991.

Milan, S. E., Lester, M., Cowley, S. W. H., Moen, J., Sandholt, P. E., and Owen, C. J.: Meridian-scanning photometer, coherent HF radar, and magnetometer observations of the cusp: a case study, Ann. Geophys., 17, 159-172, 1999.

Milan, S. E., and Lester, M.: Interhemispheric differences in the HF radar signature of the cusp region: A review through the study of a case example, Adv. Polar Upper Atmos. Res., 15, 159-177, 2001.

Milan, S. E., Lester, M., Cowley, S. W. H., Oksavik, K., Brittnacher, M., Greenwald, R. A., Sofko, G., and Villain, J.-P.: Variations in the polar cap area during two substorm cycles, Ann. Geophys., 21, 1121-1140, 2003.

Moen, J., Carlson, H. C., Milan, S. E., Shumilov, N., Lybekk, B., Sandholt, P. E., and Lester, M.: On the collocation between dayside auroral activity and coherent HF radar backscatter, Ann. Geophys., 18, 1531-1549, 2001.

Newell, P. T., and Meng, C.-I.: Mapping of the dayside ionosphere to the magnetopause according to particle precipitation events, Geophys. Res. Lett., 19, 609-612, 1992.

Newell, P. T., and Meng, C.-I., Ionospheric projection of magnetospheric regions under low and high solar wind pressure conditions, J. Geophys. Res., 99, 273-286, 1994.

Parkinson, M. L., Dyson, P. L., Pinnock, M., Devlin, J. C., Hairston, M. R., Yizengaw, E., and Wilkinson, P. J.: Signatures of the midnight open-closed magnetic field line boundary during balanced dayside and nightside reconnection, Ann. Geophys., 20, 16171630, 2002.

Pinnock, M. and Rodger, A. S.: On determining the noon polar cap boundary from SuperDARN HF radar backscatter characteristics, Ann. Geophys., 18, 1523-1530, 2001.

Pinnock, M., Rodger, A. S., Baker, K. B., Lu, G., and Hairston, M.: Conjugate observations of the day-side reconnection electric field: A GEM boundary layer campaign, Ann. Geophys., 17, 443-454, 1999.

Pinnock, M., Chisham, G., Coleman, I. J., Freeman, M. P., Hairston, M., and Villain, J.-P.: The location and rate of dayside reconnection during an interval of southward interplanetary magnetic field, Ann. Geophys., 21, 1467-1482, 2003. 
Ponomarenko, P. V., and Waters, C. L.: The role of Pc1-2 waves in spectral broadening of SuperDARN echoes from high latitudes, Geophys. Res. Lett., 30(3), 1122, doi:10.1029/2002GL016333, 2003.

Rodger, A. S., Mende, S. B., Rosenberg, T. J., and Baker, K. B.: Simultaneous optical and HF radar observations of the ionospheric cusp, Geophys. Res. Lett., 22, 2045-2048, 1995.

Sandholt, P. E., Farrugia, C. J., Øieroset, M., Stauning, P., and Denig, W. F.: Auroral activity associated with unsteady magnetospheric erosion: Observations on December 18, 1990, J. Geophys. Res., 103, 2309-2317, 1998.

Villain, J.-P., André, R., Pinnock, M., Greenwald, R. A., and Hanuise, C.: A statistical study of the Doppler spectral width of high-latitude ionospheric F-region echoes recorded with SuperDARN coherent HF radars, Ann. Geophys., 20, 1769-1781, 2002.
Woodfield, E. E., Davies, J. A., Eglitis, P., and Lester, M.: A case study of HF radar spectral width in the post midnight magnetic local time sector and its relationship to the polar cap boundary, Ann. Geophys., 20, 501-509, 2002a.

Woodfield, E. E., Davies, J. A., Lester, M., Yeoman, T. K., Eglitis, P., and Lockwood, M.: Nightside studies of coherent HF radar spectral width behaviour, Ann. Geophys., 20, 1399-1413, 2002 b.

Woodfield, E. E., Hosokawa, K., Milan, S. E., Sato, N., and Lester, M.: An inter-hemispheric, statistical study of nightside spectral width distributions from coherent HF scatter radars, Ann. Geophys., 20, 1921-1934, 2002c.

Yeoman, T. K., Lester, M., Cowley, S. W. H., Milan, S. E., Moen, J., and Sandholt, P. E.: Simultaneous observations of the cusp in optical, DMSP and HF radar data, Geophys. Res. Lett., 24, 2251-2254, 1997. 